\title{
Sexual Reproduction and Gene Flow in the Pine Pathogen Dothistroma septosporum in British Columbia
}

\author{
A. L. Dale, K. J. Lewis, and B. W. Murray \\ Natural Resources and Environmental Studies Institute, University of Northern British Columbia, 3333 University Way, Prince George, BC \\ V2N 4Z9, Canada. \\ Accepted for publication 21 August 2010.
}

\section{ABSTRACT}

Dale, A. L., Lewis, K. J., and Murray, B. W. 2011. Sexual reproduction and gene flow in the pine pathogen Dothistroma septosporum in British Columbia. Phytopathology 101:68-76.

Dothistroma septosporum has caused a serious needle blight epidemic in the lodgepole pine forests in northwest British Columbia over the past several years. Although ascocarps had been observed in British Columbia, nothing was known about the contribution of sexual reproduction, gene flow and long-distance dispersal to the epidemic. Amplified fragment length polymorphism and mating-type markers in 19 sites were used to generate population and reproductive data. Overall, evidence suggests a mixed mode of reproduction. Haplotypic diversity was high, with 79 unique and 56 shared haplotypes (possible clones) identified from 192 fungal isolates. Overall, mating-type segregation did not differ signifi- cantly from 1:1; however, random mating was rejected in most populations in the index of association and parsimony tree-length permutation analyses using the full data set and, when using clone-corrected data sets, more of the smaller populations showed random mating. Two of the smaller populations consistently showed random mating for both tests using both clone-corrected and noncorrected data. High gene flow is suggested by no differentiation between 14 of the 19 sites, several of which came from young plantations where the pathogen was not likely present prior to the current outbreak. The remaining five sites showed some level of divergence, possibly due to historic separation and endemic pathogen populations. Results indicate a high evolutionary potential and long-distance dispersal in this pathogen, important to consider in future forest management.
Dothistroma septosporum (Dorog.) M. Morelet (teleomorph = Mycosphaerella pini Rostr. Ex Munk, hereafter referred to as $D$. septosporum) is an ascomycetous foliar pathogen of many Pinus spp. worldwide $(6,22,23)$. It has been an important disease agent in exotic pine plantations in many countries of the southern hemisphere since the late 1950s (22). D. septosporum has also been found in countries of the northern hemisphere, including the United States $(16,29,44,47)$ and Canada (20), where it occurs on both native and exotic Pinus spp.; however, past outbreaks have not been as widespread or severe in the northern hemisphere as they have been in the south, until recently $(6,22,51)$.

D. septosporum has long been a part of ecosystems in British Columbia (B.C.). It was first noted in the 1960 s on both native and exotic Pinus spp. in B.C. (20,40), and recent work using tree ring records has shown an outbreak history of the pathogen reaching the length of the tree ring chronology to the early $1800 \mathrm{~s}$ (49). In addition, the teleomorph was identified on foliage from several southern B.C. localities in 1964 and 1965 (20). Recently, a large outbreak of D. septosporum in northwest B.C. has been causing concern due to the extent and severity of the outbreak, and the fact that a native species is being attacked (50,51). More than $90 \%$ of lodgepole pine plantations surveyed have suffered some damage in the current outbreak. The damage in these plantations ranges from low levels of infection to nearly $100 \%$ mortality $(50,51)$. The economic impacts of a disease outbreak of this scale can be quite severe because lodgepole pine (Pinus contorta var. latifolia Dougl. ex Loud.) is the predominant pine species in central and northern B.C. and is one of the species most commonly harvested and replanted.

Corresponding author: A. Dale; E-mail address: dale@unbc.ca

doi:10.1094/PHYTO-04-10-0121

(C) 2011 The American Phytopathological Society
D. septosporum produces asexual stromata (22) which mature 1 to 2 years after initial infection and erupt through the epidermis of the needle $(29,42,47)$. Conidia are released through early spring to late summer or early fall during moist conditions and are spread by splash dispersal $(22,29,42,44)$, which is mostly limited to within $60 \mathrm{~cm}$ from infected trees (43). In B.C., where the sexual stage has been observed, ascospore production follows in early June and continues for approximately a month (20). The lower frequency of the teleomorph and the shorter release period of ascospores suggest that primary dispersal of the fungus is through the asexual conidia $(9,15,30)$.

Little is known about long-distance dispersal capabilities or population genetic structure of $D$. septosporum, or to what extent sexual reproduction contributes to the life cycle or to disease spread. It has been shown by Groenewald et al. (25) that the fungus is heterothallic, and that single isolates contain only one of the mating-type genes, suggesting that vegetative mycelium of $D$. septosporum is haploid, which is typical of members of Ascomycota. Therefore, sexual reproduction is limited to populations that contain both mating types. In a study of 15 countries, both mating types were present in six countries, including Canada, where both mating types exist in approximately equal proportions (25). The fungus is able to survive solely through asexual reproduction, suggested by the absence of a second mating type in many southern hemisphere countries (25), the lack of sexual structures throughout much of its range (19), and the presence of a single clone throughout New Zealand (28). It is unknown how much sexual reproduction contributes to population structure and long-distance dispersal in habitats where both mating types coexist, such as B.C.

Long-distance dispersal by airborne propagules is important for the survival of many plant-pathogenic fungi, particularly those that must reestablish following harvest of crop plants or periods of unfavorable climate (11). However, long-distance dispersal is 
constrained by the ability of the pathogen to survive longer dispersal times (4) and by the availability of a susceptible host (11). Over the past four decades, the climate in northwestern B.C. has become more amenable to Dothistroma needle blight development (50), and host abundance has increased substantially (51), potentially creating greater opportunities for long-distance dispersal of the pathogen.

Quantification of long-distance dispersal in fungi is constrained by the microscopic nature of the propagules and the difficulty with identification of individuals. Of the methods described by Nathan et al. (37), genetic methods that use patterns of differentiation among populations are currently the most amenable to fungal dispersal.

Few studies have investigated the genetic structure of Dothistroma spp. Isolates originating from different countries showed different multilocus microsatellite patterns (21), and differences were found in the internal transcribed spacer sequence that separated the central U.S. strains from the others (7). In 2004, Barnes et al. (5) showed that there are two distinct lineages: $D$. pini, from the north-central region of the United States, and $D$. septosporum, with a worldwide distribution. In New Zealand, no genetic diversity was detected in the pathogen using random amplified polymorphic DNA and random amplified microsatellites (28).

It is important to consider the genetic structure of a pathogen population in forest and disease management. Genetic structure gives insight into historic movement and long-distance dispersal, ongoing gene flow, the magnitude of variation in pathogen virulence (31), and evolutionary potential (35). A population with high genetic variation has a high evolutionary potential and is more likely to quickly adapt to new conditions such as resistant hosts or changing environment (35). Gene flow among populations and recombination are two important sources of new allelic and genotypic variation that can act to increase genotypic or haplotypic diversity in a population (35). These are important biological forces to consider in disease management because they can have profound effects on how we manage for outbreaks. For example, management strategies that limit pathogen population size and gene flow among populations will be more effective in control (35) than practices that enhance gene flow. Control strategies in this instance may include limiting host stands, reducing connectivity of host stands, and increasing the distance between host stands.

Quantification of genetic diversity should give insight into reproductive and dispersal strategies of the pathogen in northwest B.C. Asexually reproducing populations display low genetic and genotypic diversity with increased levels of clonality $(14,32)$ as well as gametic phase disequilibrium $(14,36)$. Randomly mating, sexually reproducing populations display high levels of genetic and genotypic diversity and random association between alleles at different loci $(14,36)$, and both mating types should be in approximately equal proportions (36).

The objectives of this study were to (i) determine the influence of sexual reproduction on population structure and the development of the current outbreak in northwest B.C.; (ii) determine whether there is evidence for gene flow; and (iii) investigate the potential influence of mitospore (conidia) and meiospore (ascospore) dispersal on the epidemic cycle. Deviations from random mating and genetic structure were examined using data from amplified fragment length polymorphism (AFLP) (48) and mating types (25) in D. septosporum populations in northwest B.C.

\section{MATERIALS AND METHODS}

Isolate collection. Foliar samples from lodgepole pine showing signs of infection by D. septosporum were sampled from 19 sites located within the primary range of the epidemic (Fig. 1). Sampling occurred from May through September. Sixteen trees were sampled within each site, separated by $30 \mathrm{~m}$ on three or four parallel transects also separated by $30 \mathrm{~m}$.

Needles with mature stromata were surface sterilized in $10 \%$ bleach for $5 \mathrm{~min}$, rinsed in sterile water, placed on water agar, and incubated at room temperature. After 3 days, a conidial mass from one fruiting body was collected with a dissecting needle and streak plated onto fresh water agar. Plates were incubated at room temperature until hyphae were produced. A hyphal mass originating from one conidial mass from one needle of each sampled tree was transferred onto Dothistroma medium (8). Cultures were maintained at room temperature $\left(18\right.$ to $\left.20^{\circ} \mathrm{C}\right)$.

DNA extraction. DNA was extracted from fungal tissue following the method of Al-Samarrai and Schmid (2), with the following modifications: an extra chloroform cleaning step, the first precipitation also contained $\mathrm{LiCl}(0.1 \mathrm{M})$ (R. E. Bradshaw, personal communication), and the final precipitation contained $\mathrm{NaCl}(0.2 \mathrm{M})$. DNA concentration was measured on a nanodrop ND-1000 spectrophotometer (Nanodrop Technologies). Samples exceeding $200 \mathrm{ng} / \mu \mathrm{l}$ were diluted in sterile $\mathrm{H}_{2} \mathrm{O}$ to $\approx 100 \mathrm{ng} / \mu \mathrm{l}$. DNA samples used for the AFLP procedure had a 260:280 ratio $>1.6$, and contained a minimum of DNA of $25 \mathrm{ng} / \mu \mathrm{l}$.

AFLP and mating-type methods. AFLP (48) analysis was used to generate DNA fingerprints for genetic diversity estimates. AFLP methods were adapted from Alvarez and Wendel (3). Ten units of both MseI and EcoRI (New England BioLabs Ltd., Pickering, ON, Canada) were used in the restriction digestion and, in the ligation reaction, 75 pmol of both adapters and one unit of T4 DNA ligase (Invitrogen Inc., Burlington, ON, Canada) were used.

Digestion or ligation products were amplified with polymerase chain reaction (PCR) using preamplification primers (Table 1). Total reaction volumes were $20 \mu \mathrm{l}$ and contained $5 \mu \mathrm{l}$ of the ligation product, $1 \times$ PCR buffer, $1.5 \mathrm{mM} \mathrm{MgCl}_{2}, 200 \mu \mathrm{M}$ dNTPs, $0.4 \mu \mathrm{M}$ each primer, and 2 units of recombinant Taq DNA polymerase (Invitrogen Inc.). Reactions were run using the following thermal cycler conditions: 1 cycle of $72^{\circ} \mathrm{C}$ for $2 \mathrm{~min}$; followed by 20 cycles of $94^{\circ} \mathrm{C}$ for $30 \mathrm{~s}, 56^{\circ} \mathrm{C}$ for $60 \mathrm{~s}$, and $72^{\circ} \mathrm{C}$ for $1 \mathrm{~min}$; and a final extension step of $60^{\circ} \mathrm{C}$ for $30 \mathrm{~min}$. Preamplification products were then diluted $1: 10$ and used as a template for selective amplification.

Nineteen primer pairs were screened for selective amplification. Three primer pairs were chosen for the study (Table 1) based on easily distinguishable and repeatable polymorphic bands. Selective amplification reactions were $20 \mu \mathrm{l}$ and contained $1 \times$ PCR buffer, $1.5 \mathrm{mM} \mathrm{MgCl}_{2}, 300 \mu \mathrm{M}$ dNTPs, $0.4 \mu \mathrm{M}$ each primer (one of which was fluorescently labeled), 1 unit of Platinum Taq DNA polymerase (Invitrogen Inc.), and $5 \mu \mathrm{l}$ of diluted preamplification PCR product. Thermal cycler conditions were as follows: 1 cycle of $94^{\circ} \mathrm{C}$ for 3 min followed by 13 cycles of $94^{\circ} \mathrm{C}$ for $30 \mathrm{~s}, 65^{\circ} \mathrm{C}$ for $30 \mathrm{~s}$ decreasing by $0.7^{\circ} \mathrm{C}$ for each cycle, and $72^{\circ} \mathrm{C}$ for $1 \mathrm{~min}$. The stepdown was followed by 27 cycles of $94^{\circ} \mathrm{C}$ for $30 \mathrm{~s}, 56^{\circ} \mathrm{C}$ for $30 \mathrm{~s}$, and $72^{\circ} \mathrm{C}$ for $1 \mathrm{~min}$; and a final extension step of $72^{\circ} \mathrm{C}$ for $10 \mathrm{~min}$. All individuals were run in duplicate through both the preamplification and selective amplification procedures. PCR products from the selective amplification were poolplexed for each primer pair (each with different fluorescent labels) and run on a Beckman Coulter CEQ 8000 capillary sequencer.

AFLP data was analyzed with the CEQ 8000 Series Genetic Analysis System software (version 10.0; Beckman Coulter Inc., 2002). All data were visually inspected and loci were chosen based on a good signal in replicates as well as throughout the data set (i.e., fragments with an inconsistent and weak signal between runs were removed). Fragments were scored based on a minimum peak intensity of 100 , size $>80$ nucleotides, and presence in both samples.

To test for reproducibility between each AFLP step and in primer pairs, 43 samples were run in duplicate through the 
digestion and ligation procedures, and these products were then run twice through each amplification step. PCR products were stained with ethidium bromide, electrophoresed on a $1 \%$ agarose gel, and viewed under UV light. Fragments were visually compared among runs.

Mating-type genes were amplified with species-specific, matingtype-specific primers using procedures and primers developed by Groenewald et al. (25). PCR products were viewed under UV on $1 \%$ agarose gel stained with ethidium bromide. Fragments (a confirmation of $D$. septosporum) were compared with a $1-\mathrm{kb}$ size standard and scored as either mating-type 1 (820 bp) or matingtype 2 (480 bp) (25).

Data and statistical analysis. Fragments generated through the AFLP procedure were treated as individual loci with two alleles, either present or absent, and a binary data set was created. Mating-type data were converted to binary code and added as an additional locus for analysis of individual isolates (i.e., haplotype determination and clone correction, genotypic [haplotypic] diversity calculations, and the random mating tests). Due to the likelihood of balancing selection at the mating-type locus, AFLP data only was used for population level comparisons (i.e., the analysis of molecular variance [AMOVA], $F_{S T}$ and $\mathrm{Nm}$ calculations, Nei's genetic diversity, and the isolation-distance Mantel test). In order to avoid the possible effects of population structure on linkage disequilibrium (Wahlund's effect) while at the same time maximizing sample size (and power), an AMOVA was done using Arlequin 3.1 (Excoffier, Laval, and Schneider, University of
Berne, Switzerland) and $F_{S T}$ values (52) (data not shown) were used as a measure of genetic divergence in order to define populations. In all, 5 sites were treated as distinct populations, whereas 14 sites that were not significantly different from one another were treated as one population for further statistical analysis.

Haplotypes were determined in Arlequin 3.1. Two data sets were created, one which included all of the data and one that was clone corrected, leaving only one representative of each haplotype in each site (14). In order to account for possible genotyping error or PCR artifacts, individuals differing at only one locus were treated as clones. To determine whether shared haplotypes were clones, the expected frequency (probability) of each haplotype was calculated for the large population made up of the 14 undifferentiated sites by multiplying the allele frequencies for that haplotype (using clone-corrected data). The expected frequency of each haplotype was compared with the observed frequency of each to determine the likelihood that these individuals were clones or shared haplotypes (data not shown). The actual frequencies were higher than expected, suggesting that these were clones; therefore, shared haplotypes were treated as clones for the remainder of the analysis. Haplotypic diversity was calculated on the full data set, including clones, whereas genetic diversity calculations and population differentiation were done on clonecorrected data. Tests for random mating were done on both the clone-corrected and the whole data set because the reduction in sample size may reduce the power of rejecting the null hypothesis of random mating in clone-corrected data sets (36).

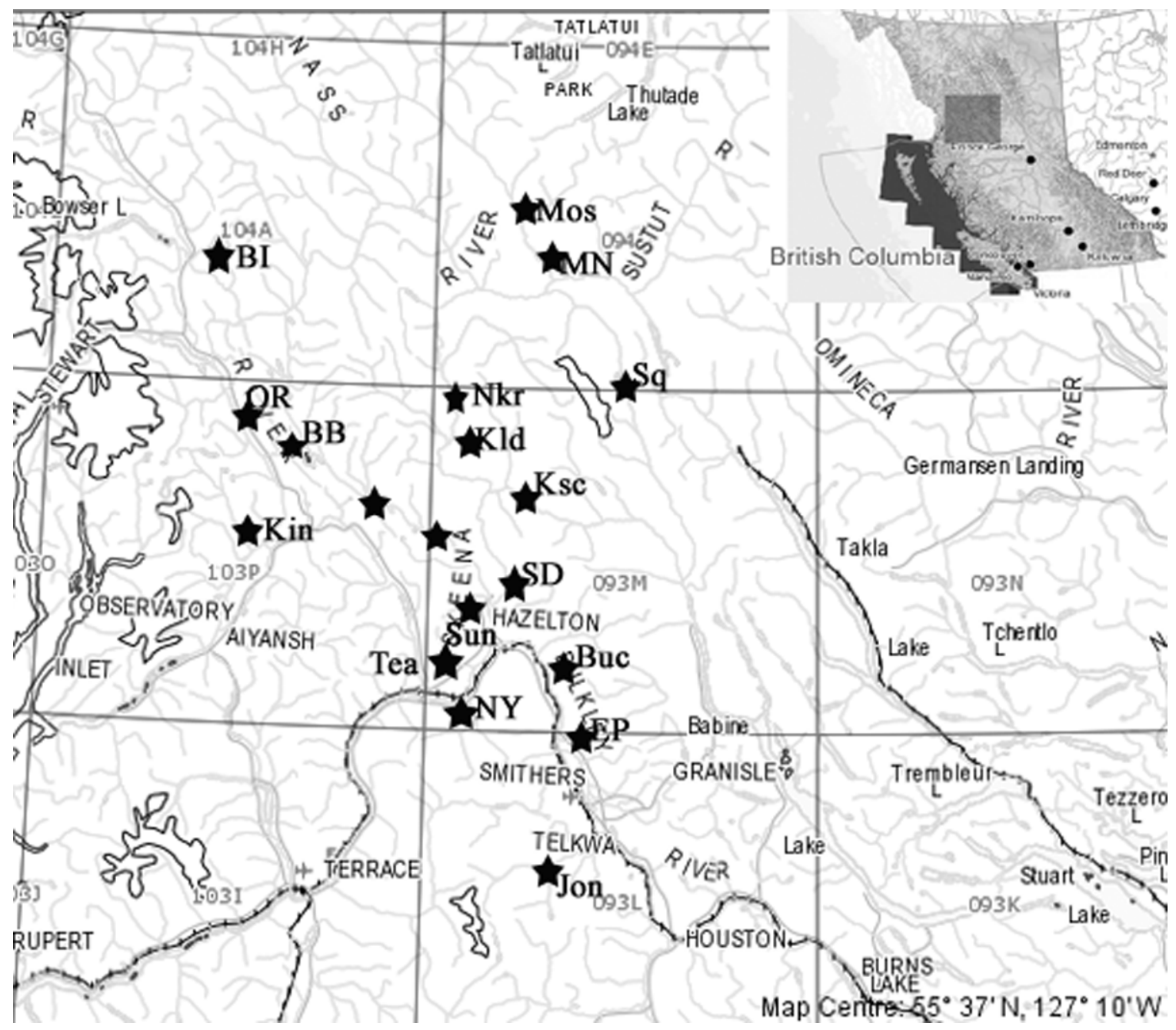

Fig. 1. Map of northwest British Columbia showing location of 19 study sites. The large Kispiox population is made up of sites BI, Mos, MN, Nkr, Kld, BB, Kin, Nan, Mit, Ksc, SD, Buc, EP, and Tea. The five divergent populations are OR, Sq, Sun, NY, and Jon, which are circled. Map created using Base Map Online Store version 4.0.1 (24). 
For each population, the proportion of polymorphic loci and the number of unique haplotypes (occurring only once in the entire data set) were calculated. Haplotypic diversity was calculated using the program MultiLocus 1.3 (1), and is the probability that two individuals sampled at random have different genotypes. It equals 1 when every individual is different and 0 when every individual is the same, and is calculated as $(n /(n-1))\left(1-\Sigma p_{i}{ }^{2}\right)$ where $n$ is the number of individuals sampled and $p_{i}$ is the frequency of the $i$ th genotype. Nei's gene diversity (39) was calculated as the average gene diversity over all loci for each population using Arlequin 3.1. Pairwise $F_{S T}$ (52) and $\mathrm{Nm}$ (45) were calculated between populations using Arlequin 3.1.

Random mating was tested using three methods. Mating-type segregation was tested using $\chi^{2}$ with an expected ratio of $1: 1(\alpha=$ $0.05)$. Significant deviations from $1: 1$ were used to reject the null hypothesis of random mating (36). Second, AFLP and matingtype data were used to calculate the index of association $\left(\mathrm{I}_{\mathrm{A}}\right)$, which is a measure of the association between loci $(1,10,36) . \mathrm{I}_{\mathrm{A}}$ was calculated using the program MultiLocus 1.3. The distance between all pairs of individuals was calculated as the number of loci that were different, and the variance of the observed distances was compared with the expected distances where there was no linkage disequilibrium. $\mathrm{I}_{\mathrm{A}}$ is 0 when there is no association between loci. $\mathrm{I}_{\mathrm{A}}$ from the observed data was compared with randomized data (500 times) to assess significant deviations from gametic equilibrium expected with random mating $(\alpha=0.05)$. To account for the possibility of physical linkage between loci, exact tests were run on all pairs of loci in each site (Arlequin 3.1), three pairs of highly linked loci were combined into three single loci, and $\mathrm{I}_{\mathrm{A}}$ was calculated again. The third test used was the parsimony tree-length permutation test (PTLPT), which compares the length of the observed tree to trees produced with randomized data (500 times). In this test, the assumption is that a clonal population should produce a single well-resolved tree, and that phylogenetic tree branches will be considerably shorter than in sexually reproducing populations because different loci reflect different patterns of descent $(13,36)$. Datasets for this test were created with MultiLocus 1.3 for use in PAUP 4.0b10 (Swofford, MA).

To examine dispersal patterns, relationships between sites were examined using the distribution of clones, the distribution of rare alleles, local spatial analysis, and genetic distance versus geographic distance. It was hypothesized that source sites would share either a geographic relationship or similar genetic characteristics. Allele frequencies were calculated on clone-corrected data for each site (Arlequin 3.1). Nei's genetic distance (38) was calculated between all sites using the program POPGENE 1.31 (Molecular Biotechnology Centre, University of Alberta, Canada) and a Mantel test was done in GenAlEx 6 (Peakall and Smouse, Australian National University, Australia) to determine whether there was a correlation between geographic distance and genetic distance (i.e., isolation-distance). To study within-site spatial patterns, three sites (BB, EP, and Sun) that had a large sample size were selected. 2D Local Spatial Analysis (GenAlEx 6) was used on full data sets to determine whether individuals were genetically correlated with their two nearest neighbors and, subsequently, their three nearest neighbors. It was expected that, in a situation where clonal reproduction was dominant, isolates taken from trees situated geographically closer to one another would be more genetically similar to one another. The three sites were then combined in a Multiple Dclass analysis (GenAlEx 6), again using the full data set. Six runs were conducted, with distance increasing by $30-\mathrm{m}$ increments in each run.

\section{RESULTS}

In total, 192 fungal isolates were collected from 19 sample sites (Fig. 1). Most viable samples were obtained from spring collections, whereas summer collections did not yield many isolates. Isolates were genotyped with both AFLP and mating-type markers. For the three AFLP primer pairs, 46 fragments, in all, were scored, of which $41 \%(n=19)$ were polymorphic and used for data analysis. The 19 polymorphic markers were found to be sufficient for population genetic analysis based on the plot of genetic diversity versus the number of loci (analysis performed in MultiLocus), which showed that 15 markers accounted for $99 \%$ of the observed variation (data not shown). For the mating-type locus, data was obtained for 177 of the individuals, all of which amplified positive as D. septosporum. The matingtype locus was added to the data set for a total of 20 polymorphic markers.

In total, 135 AFLP haplotypes were found, with 79 of those appearing only once in the entire collection of isolates. Of the remaining 56 shared haplotypes (conservatively defined as identical in all but one locus to account for possible typing error), 23 were identical for both the AFLP and mating-type loci and 33 differed at one locus. Of those 23 identical haplotypes, 6 were found only within sites whereas 17 were found both within and among sites throughout the region, with no apparent geographic relationships (data not shown). In order to examine the reasons for shared haplotypes (clonal reproduction versus chance sharing of haplotypes), expected and observed haplotype frequency were assessed in a pooled analysis of sample sites for which no genetic differences were observed (i.e., the Kispiox population; see below). The shared haplotypes were observed more frequently than expected; however, the shared haplotypes were those expected more frequently. No rare haplotypes were observed more than once. The most common haplotype (found five times) was expected only once among 1,428 individuals for a population assuming equilibrium, neutrality, and recombination. The haplotype expected most frequently (2 times in 1,000) was observed once in the data set (total dataset $=192$ individuals).

Of the 19 sites, 14 showed no significant divergence based on $F_{S T}$ values and were grouped into one population, named Kispiox. Five sites were treated as individual populations; $F_{S T}$ and predicted $\mathrm{Nm}$ values between these populations are shown in Table 2.

TABLE 1. Primers used for amplified fragment length polymorphism analysis in Dothistroma septosporum

\begin{tabular}{|c|c|c|}
\hline Primer & Function & Sequence \\
\hline Pre-EcoRI & Preamplification & GACTGCGTACCAATTC \\
\hline Pre-MseIC & Preamplification & GATGAGTCCTGAGTAAC \\
\hline $\mathrm{E}-\mathrm{ACG}(\mathrm{M}-\mathrm{A})^{\mathrm{a}}$ & Selective amplification & GACTGCGTACCAATTCACG \\
\hline $\mathrm{M}-\mathrm{CAA}(\mathrm{E}-\mathrm{A})^{\mathrm{a}}$ & Selective amplification & GATGAGTCCTGAGTAACAA \\
\hline $\mathrm{M}-\mathrm{CTG}(\mathrm{E}-\mathrm{A})^{\mathrm{a}}$ & Selective amplification & GATGAGTCCTGAGTAACTG \\
\hline E-A & Selective amplification & GACTGCGTACCAATTCA \\
\hline M-A & Selective amplification & GATGAGTCCTGAGTAAA \\
\hline MA 1.1 & Adapter & GACGATGAGTCCTGAG \\
\hline MA 1.2 & Adapter & TACTCAGGACTCAT \\
\hline EA 1.1 & Adapter & CTCGTAGACTGCGTACC \\
\hline EA 1.2 & Adapter & AATTGGTACGCAGTC \\
\hline
\end{tabular}

a Fluorescently labeled for use on Beckman Coulter CEQ8000 capillary sequencer. Primer in parentheses is the other selective primer in the pair. 
Jon and $\mathrm{Sq}$ were the most divergent populations and, if in a migration or drift equilibrium, would be expected to share less than one to two migrants per generation with the other populations. NY and OR were the least divergent and would be expected to share 8 to 15 migrants per generation with each other and the Kispiox population. Population statistics and population characteristics are presented in Table 3. Kispiox and Sq had the highest proportion of polymorphic loci (0.900), whereas Jon had the lowest (0.400). Haplotypic diversity was high in all populations ranging from 0.944 (Jon) to 1.000 (OR). Nei's gene diversity ranged from 0.219 at Sun to 0.390 at Sq.

Exact tests done on each of the 19 sample sites using the clonecorrected data set (done in Arlequin 3.1) showed three pairs of loci in linkage disequilibrium in over half of the sites; however, because the linkage was not found throughout the data set, the loci were not removed prior to analysis; instead, the pairs were combined to three single loci to create a second data set for the $I_{A}$ tests (used below).

Overall, tests for random mating show a mixed mating structure (Table 4). Both mating types were found in all populations, and there was a ratio of mating-type 1 to mating-type 2 of $96: 81$ which was not significantly different from a 1:1 segregation $\left(\chi^{2}=\right.$ $1.271, P=0.260)$. Mating-type segregation did not change from 1:1 using clone-corrected data (Table 4). Results were more skewed within individual populations. Mating-type 2 was found more frequently in Jon and Mating-type 1 was found more frequently in NY, Sq, and OR. Mating-type segregation did not differ from 1:1 in the Kispiox, Sq, or Sun populations using full data sets and, in clone-corrected data, NY also did not differ significantly from $1: 1$. In contrast, results from the $\mathrm{I}_{\mathrm{A}}$ and PTLPT suggest a more clonal structure (Table 4). Significant linkage was found in the full data set as well as in the Kispiox, Jon, NY, and Sq populations; however, $\mathrm{I}_{\mathrm{A}}$ was not significant in OR and Sun, suggesting random mating in these two populations. The same was found for the clone-corrected data; however, when using the data set with the highly linked loci combined, all five of the small populations were not significant, suggesting random mating. The large Kispiox population remained significant, suggesting a clonal structure. In the PTLPT test, when using clone-corrected data, $\mathrm{OR}$, Sun, NY, and $\mathrm{Sq}$ all showed a random mating structure because trees were not well resolved (multiple possible trees) and branch lengths were comparable with randomized data. When using full data sets, branch lengths were shorter in Jon and Sq but trees were not well resolved. In contrast, the branch lengths were considerably shorter for the Kispiox population (both the full data set and the clone-corrected data) and only one tree was found.

There were four rare alleles, two of which were shared by only Jon and Sq (Table 5). The other two rare alleles were shared by Jon, MN (a site within the Kispiox population), NY, and Sun. No geographic patterns are apparent between these sites. The Mantel test results (data not shown) showed no significant correlation between geographic distance and Nei's genetic distance $\left(R^{2}=\right.$ $0.023, P=0.220$ ). In the 2D Local Spatial Analysis, Sun and BB show no significant correlations with their two nearest neighbors, whereas EP showed 4 of 14 trees significantly correlated with their nearest neighbors. When looking at the three nearest neighbors, only one tree in EP showed a significant correlation with neighbors (data not shown). In the Multiple Dclass analysis, the correlation is highest with the shortest distances and decreases as the distance increases but, overall, the correlation is low ( 0.076 to $0.000)$ and not significant for any of the distance classes.

\section{DISCUSSION}

Sexual reproduction appears to be a regular part of the lifecycle of D. septosporum populations in northwest B.C. Mating types were in equilibrium throughout the region as well as in half of the individual populations. Sexual reproduction has been suspected in pathogen populations in this region since the sexual stage was found by Funk and Parker in 1966 (20); however, given the extent of the asexual stage $(6,9,19,23)$, a more clonal structure was expected. Some possible clones (shared haplotypes) were found; however, these were few and randomly distributed throughout the study range. It is suspected that intensive sampling within trees as well as between closely situated trees would uncover a higher frequency of clones because the asexual conidia are splash dis-

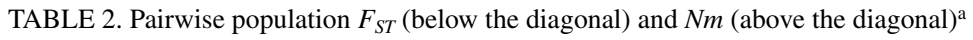

\begin{tabular}{|c|c|c|c|c|c|c|}
\hline \multirow[b]{2}{*}{ Population } & \multicolumn{6}{|c|}{ Population } \\
\hline & Kispiox & Jon & NY & OR & $\mathrm{Sq}$ & Sun \\
\hline Kispiox & & 0.87552 & 8.48008 & 11.8886 & 2.66416 & 2.18377 \\
\hline Jon & 0.36350 & $\ldots$ & 0.90575 & 0.56355 & 2.18042 & 0.48607 \\
\hline NY & 0.05568 & 0.35568 & $\ldots$ & 15.04721 & 2.39343 & 1.23237 \\
\hline OR & 0.04036 & 0.47012 & 0.03216 & $\ldots$ & 2.68056 & 0.61371 \\
\hline $\mathrm{Sq}$ & 0.15802 & 0.18654 & 0.17281 & 0.15721 & $\ldots$ & 0.77962 \\
\hline Sun & 0.18630 & 0.50706 & 0.28862 & 0.44895 & 0.39074 & $\ldots$ \\
\hline
\end{tabular}

${ }^{\text {a }}$ Calculated between distinct populations using clone-corrected data.

TABLE 3. Population genetic statistics for Dothistroma septosporum populations

\begin{tabular}{|c|c|c|c|c|c|c|c|}
\hline \multirow[b]{2}{*}{ Population } & \multirow[b]{2}{*}{ Forest type } & \multicolumn{2}{|c|}{ Sample size } & \multirow[b]{2}{*}{ Loci $^{b}$} & \multirow[b]{2}{*}{ No. of haplotypes ${ }^{\mathrm{c}}$} & \multicolumn{2}{|c|}{ Diversity } \\
\hline & & Full data & $\mathrm{CC}^{\mathrm{a}}$ & & & Haplotypic ${ }^{\mathrm{d}}$ & Nei's gene ${ }^{\mathrm{e}}$ \\
\hline Kispiox & Mixed & 133 & 107 & 0.900 & 68 & 0.995 & 0.300 \\
\hline Jon & Natural & 9 & 5 & 0.400 & 4 & 0.944 & 0.232 \\
\hline NY & Natural & 16 & 11 & 0.750 & 9 & 0.975 & 0.311 \\
\hline OR & Plantation & 8 & 6 & 0.500 & 4 & $1.000^{\mathrm{f}}$ & 0.220 \\
\hline $\mathrm{Sq}$ & Natural & 10 & 7 & 0.900 & 7 & 0.978 & 0.390 \\
\hline Sun & Plantation & 16 & 12 & 0.600 & 9 & 0.983 & 0.219 \\
\hline
\end{tabular}

${ }^{\text {a }}$ Clone-corrected (CC) data. Clone correction included identical haplotypes and haplotypes differing by only one locus.

b Proportion of polymorphic loci.

c Number of unique haplotypes.

d Haplotypic diversity (Multilocus 1.3, based on 1) calculated using complete data set.

e Gene diversity calculated on CC data using Arlequin 3.1; average gene diversity over loci.

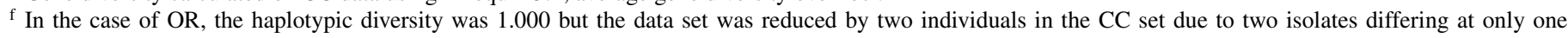
amplified fragment length polymorphism locus. 
persed $(22,29,42,44)$. Even though sexual reproduction appeared to be the dominant influence on population structure, there was still a significant effect from asexual reproduction. Both the $\mathrm{I}_{\mathrm{A}}$ and the PTLPT showed evidence for a more clonal population structure, specifically in the total data set and in the large Kispiox population. In a strictly asexually reproducing population, it is expected that haplotypic diversity would be low whereas, in populations undergoing recombination, haplotypic diversity would be high (36). High levels of haplotypic diversity were found and, in one population, every individual tested was genetically distinct. It is hypothesized that sexual reproduction is a regular part of the life cycle of this pathogen in order to produce the near 1:1 ratio of the two mating types and the observed levels of haplotypic diversity. In addition, in the clone-corrected data, the PTLPT results suggest random mating in four populations, and the $I_{A}$ results suggest random mating in two populations; however, when the linked loci were combined, all five of the small clonecorrected populations showed random mating. Both the $\mathrm{I}_{\mathrm{A}}$ results and the PTLPT show a clonal structure in the large Kispiox population, even when the linked loci are combined.

There have been other studies on ascomycetous pathogens with similar life cycles that have shown contradicting results due to mixed modes of mating. Cortesi et al. (17) found evidence of both reproductive modes in Erysiphe necator in vineyards in Italy. They found high haplotypic diversity, both mating types in a 1:1 ratio, and haplotypes were not spatially autocorrelated. In contrast, $\mathrm{I}_{\mathrm{A}}$ showed a more clonal population structure, which is similar to results of this study. Similar to D. septosporum, E. necator's primary source of inoculum is thought to be the conidia, which are also dispersed over short distances. Similar results were also found in the banana pathogen M. musicola, which has a short ascospore release period and a longer period of release for conidia (27), as is thought to occur in D. septosporum. In addition, ascospores of M. musicola are also wind dispersed and conidia splash dispersed. Random mating was rejected in the majority of populations of $M$. musicola studied, likely due to the conidia acting as the primary source of inoculum (27).

The contradicting results from the analysis of mating type and from the $\mathrm{I}_{\mathrm{A}}$ or PTLPT tests have several possible explanations. Observations of linkage disequilibrium may result from deviations from random mating such as mating among related individuals in small populations (34) or in spatially restricted neighborhoods (36). Linkage disequilibrium can also be caused by factors other than reproductive mode such as a tight physical

TABLE 4. Random mating tests on Dothistroma septosporum on full data set and on clone-corrected (CC) data set

\begin{tabular}{|c|c|c|c|c|c|c|c|c|c|c|}
\hline \multirow[b]{2}{*}{ Population $^{\mathrm{a}}$} & \multicolumn{4}{|c|}{ Index of association $\left(\mathrm{I}_{\mathrm{A}}\right)^{\mathrm{b}}$} & \multicolumn{3}{|c|}{ PTLPT $^{\mathrm{c}}$} & \multicolumn{3}{|c|}{ Mating type segregation } \\
\hline & $\mathrm{I}_{\mathrm{A}}$ & $P$ & $\mathrm{I}_{\mathrm{A}}^{\mathrm{LC}}$ & $P^{\mathrm{LC}}$ & $\mathrm{L}$ & $\mathrm{L}^{*}$ & $P$ & $\mathrm{M} 1: \mathrm{M} 2^{\mathrm{d}}$ & $\chi^{2 \mathrm{e}}$ & $P$ \\
\hline Kispiox & 0.951 & $<0.002$ & 0.561 & $<0.002$ & $151(1)$ & 226 & 0.000 & $60: 63$ & 0.073 & 0.787 \\
\hline Jon & 2.851 & $<0.002$ & 1.336 & 0.002 & $11(3)$ & 13 & 0.000 & $1: 5$ & $\ldots$ & $\ldots$ \\
\hline NY & 1.117 & $<0.002$ & 0.525 & 0.008 & $30(4)$ & 30 & 0.004 & $13: 3$ & 6.250 & 0.012 \\
\hline $\mathrm{Sq}$ & 1.671 & $<0.002$ & 1.064 & 0.002 & $26(4)$ & 28 & 0.000 & $8: 2$ & 3.600 & 0.058 \\
\hline OR & 0.446 & 0.130 & 0.446 & 0.112 & $13(5)$ & 12 & 0.326 & $7: 1$ & $\ldots$ & $\ldots$ \\
\hline Sun & 0.235 & 0.084 & 0.111 & 0.224 & $24(3)$ & 19 & 0.770 & $7: 7$ & 0.000 & 1.000 \\
\hline Total & 0.938 & $<0.002$ & 0.458 & $<0.002$ & $211(2)$ & 353 & 0.000 & $96: 81$ & 1.271 & 0.260 \\
\hline Kispiox CC & 0.813 & $<0.002$ & 0.460 & $<0.002$ & 139 (1) & 196 & 0.000 & $51: 49$ & 0.04 & 0.841 \\
\hline Jon CC & 2.250 & $<0.002$ & 0.778 & 0.062 & $9(2)$ & 9 & 0.020 & $0: 3$ & $\ldots$ & $\ldots$ \\
\hline NY CC & 0.460 & 0.034 & -0.016 & 0.464 & $30(3)$ & 26 & 0.354 & $8: 3$ & 2.273 & 0.132 \\
\hline $\mathrm{Sq} \mathrm{CC}$ & 0.827 & 0.032 & 0.391 & 0.152 & $25(2)$ & 23 & 0.114 & $5: 2$ & $\ldots$ & $\ldots$ \\
\hline OR CC & 0.295 & 0.248 & 0.295 & 0.250 & $12(3)$ & 10 & 0.450 & $5: 1$ & $\ldots$ & $\ldots$ \\
\hline Sun CC & -0.019 & 0.488 & -0.144 & 0.796 & $24(1)$ & 18 & 0.998 & $5: 7$ & 0.333 & 0.564 \\
\hline Total CC & 0.762 & $<0.002$ & 0.362 & $<0.002$ & $192(1)$ & 274 & 0.000 & $74: 65$ & 0.583 & 0.445 \\
\hline
\end{tabular}

${ }^{a}$ Kispiox $=14$ sites that are genetically undifferentiated from each other and Total $=$ total of all populations.

b Values obtained in Multilocus, with 500 randomizations of data; LC = linkage-corrected data set (highly linked loci combined).

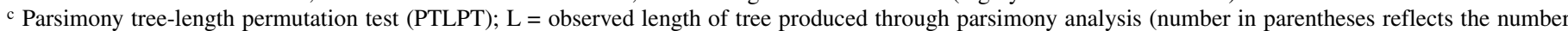
of most parsimonious trees found) and $\mathrm{L}^{*}=$ length of the shortest tree in the randomized data (500 replicates).

d Sample size for mating type (M1 and M2) is less than $N$ in some populations due to missing data.

e The $\chi^{2}$ probability is only calculated when expected values are $>5$ in each cell.

TABLE 5. Population allele frequencies for clone-corrected amplified fragment length polymorphism data

\begin{tabular}{|c|c|c|c|c|c|c|}
\hline \multirow[b]{2}{*}{ Locus } & \multicolumn{6}{|c|}{ Population allele frequency } \\
\hline & Kispiox & Jon & NY & OR & $\mathrm{Sq}$ & Sun \\
\hline $512 \mathrm{D} 2$ & 0.206 & 0 & 0.727 & 0.167 & 0.286 & 0.500 \\
\hline 646D2 & 0.953 & 1.000 & 0.909 & 1.000 & 0.857 & 1.000 \\
\hline 707D2 & 0.458 & 0 & 0.273 & 0.167 & 0.286 & 0.750 \\
\hline 123D3 & 0.523 & 0.400 & 0.545 & 0.667 & 0.714 & 0 \\
\hline 169D3 & 0.860 & 1.000 & 1.000 & 0.667 & 0.714 & 0.667 \\
\hline 181D3 & 0 & 1.000 & 0 & 0 & 0.571 & 0 \\
\hline 243D3 & 0.645 & 0 & 0.545 & 0.500 & 0.143 & 0.750 \\
\hline 254D3 & 0.561 & 0 & 0.455 & 0.833 & 0.714 & 0.083 \\
\hline 285D3 & 0.579 & 0.400 & 0.727 & 0.833 & 0.714 & 0 \\
\hline 352D3 & 0.621 & 0.400 & 0.727 & 1.000 & 0.714 & 0 \\
\hline 793D3 & 0.785 & 1.000 & 0.727 & 0.667 & 0.857 & 0.917 \\
\hline 950D3 & 0.093 & 0.200 & 0 & 0 & 0.286 & 0 \\
\hline 186D4 & 1.000 & 0.200 & 1.000 & 1.000 & 0.429 & 1.000 \\
\hline 383D4 & 0.841 & 1.000 & 1.000 & 1.000 & 0.714 & 0.833 \\
\hline 386D4 & 0.860 & 1.000 & 0.727 & 1.000 & 0.714 & 1.000 \\
\hline 495D4 & 0.430 & 1.000 & 0.636 & 0.667 & 0.857 & 0.333 \\
\hline 745D4 & 0.598 & 0.600 & 0.909 & 1.000 & 0.143 & 0.500 \\
\hline 855D4 & 0.028 & 0.600 & 0.181 & 0 & 0 & 0.083 \\
\hline 862D4 & 0.028 & 0.600 & 0.181 & 0 & 0 & 0.083 \\
\hline
\end{tabular}


linkage in loci, selection, gene flow, and drift (36) and undetected population structure. Evidence for linkage disequilibrium was still observed after correcting for physical linkage, and populations were defined prior to testing for random mating in order to account for possible effects of genetic structure. There are also factors that may decrease the apparent contribution of asexual reproduction. Small amounts of sexual recombination can have a large impact on population structure $(13,36)$. Sampling scale can also affect results. More clonal haplotypes may be found by decreasing the geographical scale of a study and increasing sampling intensity within hosts in pathogens with splash-dispersed conidia $(14,18)$. However, the contradicting results may themselves be due to the life cycle of $D$. septosporum. The period of sexual reproduction is thought to be a lot shorter than the period of asexual reproduction, only approximately a month for ascospore production (20) versus early spring to late summer or early fall for conidia.

Another possible explanation for the contradicting results is that, during endemic versus epidemic periods, the relative frequencies of sexual and asexual reproduction change dependent on environmental conditions. Evans (19) found that, in Central America, where both reproductive stages were present, initial collections were mainly of the sexual stage whereas later collections were of the asexual stage. If late spring and summer conditions became too dry and hot for conidial development, then the relative frequency of sexual reproduction would be higher; however, if summer temperatures were moderate and humidity and rainfall higher, then the relative frequency of asexual reproduction would be higher. In northwest B.C., Woods et al. (50) found a strong spatial correlation between the area affected by the Dothistroma epidemic and an increase in mean summer precipitation, as well as an increase in consecutive rainfall at $>16,18$, and $20^{\circ} \mathrm{C}$ which coincided with the outbreak. Welsh et al. (49) also found a largescale spatial synchrony between increased spring precipitation and August minimum temperatures with the current outbreak. These conditions are favorable for conidial development and dissemination. The contradicting results could be due to a carryover from the genetic structure during the endemic period if that period favored sexual reproduction.

In addition to evidence that supports sexual reproduction in the studied populations, there is also evidence of high gene flow among the sites in this region. Of the 19 sites, 14 were not genetically differentiated; many of the $F_{S T}$ values were zero and the predicted $\mathrm{Nm}$ values were infinite. Some of the sites within this group were separated by large geographic distances or mountain ranges. Although low divergence could be due to shared ancestral polymorphisms, gene flow is a more plausible explanation because eight of these host stands are relatively young plantations (estimated at $\approx 20$ to 30 years old) and much of this region would not have been previously inhabited by a suitable host species. Natural mature stands in the region consist largely of western hemlock and subalpine fir, with only a small component of pine (9\%) (51). Managed forests (plantations <20 years old) are dominated by lodgepole pine (36\%) and interior spruce $(45 \%)$ (51). For a large-scale epidemic, inoculum would have to come from dispersal from other host stands, suggesting long-distance or aerial dispersal by this pathogen.

D. septosporum is thought to reproduce primarily via asexual conidia $(15,30)$ which are splash dispersed $(22,29,42,44)$ and have a limited dispersal range (43). The ascospores are thought to be wind or mist dispersed, with a potential for long-distance dispersal $(6,23)$. These dispersal characteristics would produce a genetic pattern where clones are found in small clusters versus over a wide geographic range (35). The high haplotypic diversity and low number of clones between sites, the low levels of population divergence, and the lack of local spatial correlation between sampling points in this study support the hypothesis that most of the long-range dispersal is through the ascospores. This is similar to findings by Parrent et al. (41), who also attribute a lack of local spatial structure in the fungus Datronia caperata to dispersal through basidiospores. In addition, results from the Mantel test show no correlation between genetic and geographic distance where sites were located at least $7 \mathrm{~km}$ apart, with a maximum distance of $230 \mathrm{~km}$. In contrast to this study, genetic differentiation was found between populations of the birch endophyte, Gnomonia setacea (33), separated by only $20 \mathrm{~km}$. The ascospores in this species are thought to be rain dispersed, and dispersal is thought to occur on a limited scale (33).

There were 23 shared-identical haplotypes found randomly distributed throughout the region. Of these shared haplotypes, 6 were found only within a site and 17 were randomly distributed both between and within sites. These individuals may share haplotypes by chance, or they could be clones. Evidence to date suggests that dispersal of the conidia is limited (43); however, it has been suggested that some long-distance dispersal of the conidia may occur in fog belts though that is thought to be minimal (22). The wide spatial distribution of what could be clones in the current study may lend support to this hypothesis. Further studies would be required to determine the reason behind the shared haplotypes and to confirm this suggestion.

Five of the populations remained significantly different from the main group regardless of their geographical distance from sites in that group. Two rare alleles were shared by Sq and Jon, and two other rare alleles were shared by Sun, Jon, NY, and MN (part of the Kispiox population), suggesting a relationship between these sites. These sites are not close to one another; however, Sq, Jon, NY, and MN all came from natural pine stands and Sun was located next to a natural pine stand. Two of these populations, NY and Sq, have the highest gene diversity $(0.311$ and 0.390 , respectively). The shared rare alleles, the fact that these isolates all came from natural pine stands, and the higher gene diversity all suggest that the pathogen has existed at these sites prior to becoming established in the other sites. It is likely that the source for this epidemic came from natural pine stands and that this pathogen has long been a part of the ecosystem. This is in agreement with findings of Welsh et al. (49), who reconstructed historical outbreaks of the pathogen in the same region as far back as the early 1800s (the limit of the tree-ring record in that study). An increase in hosts over the region (51) and recent favorable weather conditions $(49,50)$ appear to have led to an expansion of existing pathogen populations rather than a change in pathogen virulence.

Sun is the most distinct site, has the lowest gene diversity (0.219), and many of the alleles are fixed in this population. It is hypothesized that this population originated from an adjacent partially harvested pine stand. Partial harvest of the host stand could have removed part of the source population's gene pool, reducing the gene diversity available to infect the new host stand. It is also possible that weather patterns in the area may restrict gene flow between the new Sun population and the sites within the Kispiox population, keeping Sun distinct.

In 1984, Evans (19) hypothesized that Dothistroma septosporum originated in Central America; however, North America could not be ruled out as the center of origin because the pathogen is endemic to native species in the United States and Canada. In the current study, a long-term existence of the pathogen is suggested by the presence of both mating types in equal proportions, and genetic patterns support the hypothesis that the pathogen maintains endemic levels on lodgepole pine, which is native to the area. Northwest B.C. is on the outermost edge of the pathogen's natural range, where historically unfavorable climate kept the population under control and limited disease pressure and selection for resistant host genotypes, which may account for the high susceptibility of a native host species. Zhan et al. (53) studied the global population structure of $M$. graminicola and found the highest average gene diversity values (0.503) in populations from the Middle East, where the pathogen was hypothe- 
sized to have originated. A comparison of gene diversity in the global population structure of D. septosporum would help to clarify this pathogen's origin.

Given the very uncommon observation of the teleomorph during the current outbreak, a more clonal population structure was expected than what was actually observed. It is possible that D. septosporum is predominantly mitosporic, with rare sexual recombination, and that the haplotypic diversity observed is due to somatic recombination, mutation, or immigration of new genotypes from separate populations (12). However, the lack of evidence for genetic diversity caused by mutation or somatic recombination in regions where the fungus appears to be reproducing only asexually $(25,28)$, and the historically sparse patches of the host species, which would limit immigration of novel haplotypes, does not support this hypothesis.

Alternatively, D. septosporum in the study area appears to fit the classic epidemic cycle described by Taylor et al. (46) for heterothallic fungi with mitospores. This cycle has two phases, with the first being the establishment of new, genetically distinct, infection centers by primary inoculum (ascospores), followed by secondary spread of the infection centres by conidia. Historically, drier weather in the area and infrequent occurrence of the host most likely limited the second phase of the epidemic cycle, therefore favoring ascospore production and dispersal. Local populations may have undergone extinction (or near extinction) and recolonization cycles (11) brought about by dry periods and disturbance, and succession processes causing changes to the location and abundance of the host. Recolonization in that patchy environment would have required long-distance dispersal of propagules, and most of the biological and genetic evidence suggests that long-distance dispersal in D. septosporum is primarily through sexually produced ascospores. Changes in pathogen biology brought about by directional change in weather patterns $(49,50)$ and human-caused changes in spatial distribution of the host (51) have contributed to the perception that D. septosporum is a primarily asexual fungus, a phenomenon described in general for fungi by Taylor et al. (46).

At the beginning of the current study, the existence of sexual reproduction and possible impacts on genetic structure were unknown. In addition, it was unknown whether there was any gene flow or at what scale it occurred. Therefore, an "intermediate" sampling scheme was chosen to address the population structure at a regional level. Future studies could include more intensive fine-scale sampling to test the hypothesis of a clustered clonal structure within trees and possible adjoining trees. In addition, more regions could be added to determine whether gene flow occurs between regions and to determine limitations to migration. Expanding to a continental level could address some of the questions regarding the origin of this pathogen.

The small sample sizes were a limitation in this study because they can inflate measures of genetic differentiation (26) and can also decrease the power of the statistical tests for random mating (36). Increasing the sample size in future studies would enable further clarification of the patterns between some of the natural stands and plantations. Studies conducted during endemic periods would also help to confirm some of the hypotheses on the contributions of the two reproductive modes.

D. septosporum populations in northwest B.C. have a high evolutionary potential (the potential to adapt in new or changing environments) (35) based on the existing level of genetic diversity and the presence of sexual reproduction. There is evidence of high gene flow among many of the sites as well as a large dispersal range. A long dispersal range means that neighboring regions containing pine are also at risk during an epidemic. If forest management continues to create unbroken corridors of pine, then the pathogen has the ability to invade new regions. This is especially of concern given that Woods et al. (50) have shown that the pathogen is likely responding to directional global climate change rather than periodic fluctuations in climate patterns. If this is the case, then the current levels of pathogen activity may continue rather than decline.

\section{ACKNOWLEDGMENTS}

Funding for this work was provided by the BC Forest Science Program. We thank C. Alstrom-Rapaport, A. Woods, and R. Bradshaw for advice and assistance during this project; $\mathrm{C}$. Welsh for field assistance; R. Hamelin for his helpful comments and suggestions as the manuscript was prepared; K. Egger for advice; and two anonymous reviewers for their helpful comments during the submission process.

\section{LITERATURE CITED}

1. Agapow, P. M., and Burt, A. 2001. Indices of multilocus disequilibrium. Mol. Ecol. Notes 1:101-102.

2. Al-Samarrai, T. H., and Schmid, J. 2000. A simple method for extraction of fungal genomic DNA. Lett. Appl. Microbiol. 30:53-56.

3. Alvarez, I., and Wendel, J. F. 2006. Cryptic interspecific introgression and genetic differentiation within Gossypium aridum (Malvaceae) and its relatives. Evolution 60:505-517.

4. Aylor, D. E. 2003. Spread of plant disease on a continental scale: role of aerial dispersal of pathogens. Ecology 84:1989-1997.

5. Barnes, I., Crous, P. W., Wingfield, B. D., and Wingfield, M. J. 2004. Multigene phylogenies reveal that red band needle blight of Pinus is caused by two distinct species of Dothistroma, D. septosproum and D. pini. Stud. Mycol. 50:551-565.

6. Bradshaw, R. E. 2004. Dothistroma (red-band) needle blight of pines and the dothistromin toxin: a review. For. Pathol. 34:163-185.

7. Bradshaw, R., Bhatnagar, D., Ganley, R., Gillman, C., Monahan, B., and Seconi, J. 2002. Dothistroma pini, a forest pathogen, contains homologs of aflatoxin biosynthetic pathway genes. Appl. Environ. Microbiol. 68:2885-2892.

8. Bradshaw, R. E., Gangley, R. J., Jones, W. T., and Dyer, P. S. 2000. High levels of dothistromin toxin produced by the forest pathogen Dothistroma pini. Mycol. Res. 104:325-332.

9. Braun, C. 2009. The role of weather and topography in the development of Dothistroma septosporum. Thesis, University of Northern British Columbia, Prince George, BC, Canada.

10. Brown, A. H. D., Feldman, M. W., and Nevo, E. 1980. Multilocus structure of natural populations of Hordeum spontaneum. Genetics 96:523-536.

11. Brown, J. K., and Hovmøller, M.S. 2002. Aerial dispersal of pathogens on the global and continental scales and its impact on plant disease. Science 297:537-541.

12. Burdon, J. J., and Silk, J. 1997. Sources and patterns of diversity in plantpathogenic fungi. Phytopathology 87:664-669.

13. Burt, A., Carter, D. A., Koenig, G. L., White, T. J., and Taylor, J. W. 1996. Molecular markers reveal cryptic sex in the human pathogen Coccidioides immitis. Proc. Natl. Acad. Sci. USA 93:770-773.

14. Chen, R. S., and McDonald, B. A. 1996. Sexual reproduction plays a major role in the genetic structure of populations of the fungus Mycosphaerella graminicola. Genetics 142:1119-1127.

15. Cobb, F., Uhrenholdt, B., and Krohn, R. 1969. Epidemiology of Dothistroma pini needle blight on Pinus radiata. Phytopathology 59:1021-1022.

16. Cobb, F. W., and Miller, D. R. 1968. Hosts and geographic distribution of Scirrhia pini-the cause of red band needle blight in California. J. For. 66:930-933.

17. Cortesi, P., Ottaviani, M.-P., and Milgroom, M. 2004. Spatial and genetic analysis of a flag shoot subpopulation of Erysiphe necator in Italy. Phytopathology 94:544-550.

18. Douhan, G. W., Peever, T. L., and Murray, T. D. 2002. Multilocus population structure of Tapesia yallundae in Washington State. Mol. Ecol. 11:2229-2239.

19. Evans, H. C. 1984. The genus Mycosphaerella and its anamorphs Cercoseptoria, Dothistroma and Lecanosticta on pines. CMI Mycol. Pap. No. 153. Commonwealth Mycological Institute, Surrey, UK.

20. Funk, A., and Parker, A. K. 1966. Scirrhia pini N. sp., the perfect state of Dothistroma pini Hulbary. Can. J. Bot. 44:1171-1176.

21. Ganley, R. J., and Bradshaw, R. E. 2001. Rapid identification of polymorphic microsatellite loci in a forest pathogen, Dothistroma pini, using anchored PCR. Mycol. Res. 105:1075-1078.

22. Gibson, I. A. S. 1972. Dothistroma Blight of Pinus radiata. Annu. Rev. Phytopathol. 10:51-72.

23. Gibson, I. A. S. 1974. Impact and control of Dothistroma blight of pines. Eur. J. For. Pathol. 4:89-100.

24. Government of British Columbia. 2010. Base Map Online Store version 
4.0.1. Available from http://openmaps.gov.bc.ca/imfows13/imf.jsp?site=idt

25. Groenewald, M., Barnes, I., Bradshaw, R. E., Brown, A. V., Dale, A., Groenewald, J. Z., Lewis, K. J., Wingfield, B. D., Wingfield, M. J., and Crous, P. W. 2007. Characterization and distribution of mating type genes in the Dothistroma needle blight pathogens. Phytopathology 97:825-834.

26. Hamelin, R. C. 2006. Molecular epidemiology of forest pathogens: From genes to landscape. Can. J. Plant Pathol. 28:167-181.

27. Hayden, H. L., Carlier, J., and Aitken, E. A. B. 2005. The genetic structure of Australian populations of Mycosphaerella musicola suggests restricted gene flow at the continental scale. Phytopathology 95:489-498.

28. Hirst, P., Richardson, T., Carson, S., and Bradshaw, R. 1999. Dothistroma pini genetic diversity is low in New Zealand. N. Z. J. For. Sci. 29:459472.

29. Hulbary, R. L. 1941. A needle blight of Austrian pine. Ill. Nat. Hist. Surv. Bull. 21:231-236.

30. Karadzic, D. 1989. Scirrhia pini Funk et Parker. Life cycle of the fungus in plantations of Pinus nigra Arn. in Serbia. Eur. J. For. Pathol. 19:231236.

31. Kinloch, B. B. Jr., Westfall, R. D., White, E. E., Gitzendanner, M. A., Dupper, G. E., Foord, B. M., and Hodgskiss, P. D. 1998. Genetics of Cronartium ribicola. IV. Population structure in western North America. Can. J. Bot. 76:91-98.

32. Kohn, L. M. 1995. The clonal dynamic in wild and agricultural plantpathogen populations. Can. J. Bot. 73 (Suppl. 1):S1231-S1240.

33. Lappalainen, J. H., and Yli-Mattila, T. 1999. Genetic diversity in Finland of the birch endophyte Gnomonia setacea as determined by RAPD-PCR markers. Mycol. Res. 103:328-332.

34. McDonald, B. A. 2004. Population genetics of plant pathogens. The Plant Health Instructor. Online publication. DOI: 10. 1094/PHI-A-2004-0524-01.

35. McDonald, B. A., and Linde, C. 2002. Pathogen population genetics, evolutionary potential, and durable resistance. Annu. Rev. Phytopathol. 40:349-379.

36. Milgroom, M. G. 1996. Recombination and the multilocus structure of fungal populations. Annu. Rev. Phytopathol. 34:457-477.

37. Nathan, R., Perry, G., Cronin, J., Strand, A., and Cain, M. 2003. Methods for estimating long-distance dispersal. Oikos 103:261-273.

38. Nei, M. 1973. Analysis of gene diversity in subdivided populations. Proc. Natl. Acad. Sci. USA 70:3321-3323.
39. Nei, M. 1987. Molecular Evolutionary Genetics. Columbia University Press, New York

40. Parker, A. K., and Collis, D. G. 1966. Dothistroma needle blight of pines in British Columbia. For. Chron. 42:160-161.

41. Parrent, J. L., Garbelotto, M., and Gilbert, G. S. 2004. Population genetic structure of the polypore Datronia caperata in fragmented mangrove forests. Mycol. Res. 108:403-410.

42. Peterson, G. W. 1967. Dothistroma needle blight of Austrian and ponderosa pines: epidemiology and control. Phytopathology 57:437-441.

43. Peterson, G. W. 1973. Infection of Austrian and ponderosa pines by Dothistroma pini in eastern Nebraska. Phytopathology 63:1060-1063.

44. Rogerson, C. T. 1953. Kansas mycological notes, 1951. Trans. Kans. Acad. Sci. 56:53-57.

45. Slatkin, M. 1991. Inbreeding coefficients and coalescence times. Genet. Res. 58:167-175.

46. Taylor, J., Jacobsen, D., and Fisher, M. 1999. The evolution of asexual fungi: reproduction, speciation and classification. Annu. Rev. Phytopathol. 37:197-246.

47. Thyr, B. D., Shaw, C. G., III. 1964. Identity of the fungus causing red band disease on pines. Mycologia 56:103-109.

48. Vos, P., Hogers, R., Bleeker, M., Reijans, M., van de Lee, T., Hornes, M., Frijters, A., Pot, J., Peleman, J., Kulper, M., and Zabeau, M. 1995. AFLP a new technique for DNA fingerprinting. Nucleic Acids Res. 23:44074414.

49. Welsh, C., Lewis, K. J., and Woods, A. 2009. The outbreak history of Dothistroma needle blight; an emerging forest disease in northwest British Columbia, Canada. Can. J. For. Res. 39:2505-2519.

50. Woods, A., Coates, K. D., and Hamann, A. 2005. Is an unprecedented Dothistroma needle blight epidemic related to climate change? BioScience 55:761-769.

51. Woods, A. J. 2003. Species diversity and forest health in northwest British Columbia. For. Chron. 79:892-897.

52. Wright, S.1951. The genetical structure of populations. Ann. Eugen. (Lond.) 1:323-334.

53. Zhan, J., Pettway, R. E., and McDonald, B. A. 2003. The global genetic structure of the wheat pathogen Mycosphaerella graminicola is characterized by high nuclear diversity, regular recombination, and gene flow. Fungal Genet. Biol. 38:286-297. 